\title{
An Empirical Study on the Intention to Reuse Computational Science and Engineering Platforms: A Case Study of EDISON
}

\author{
Noori On ${ }^{1}$, Gi-Myeong Ryu ${ }^{1}$, Myoung-Ju Koh ${ }^{1}$, Jongsuk Ruth Lee ${ }^{1 *}$ and Nam-Gyu Kim ${ }^{*}$ \\ ${ }^{1}$ Division of National Supercomputing, Korea Institute of Science and Technology Information \\ Daejeon, South Korea \\ [e-mail: claireon, symsonic, myju, jsruthlee, ssgyu@kisti.re.kr] \\ *Corresponding author: Jongsuk Ruth Lee and Nam-Gyu Kim
}

Received February 21, 2020; revised April 29, 2020; revised June 27, 2020; accepted July 21, 2020; published August 31, 2020

\begin{abstract}
The computational science and engineering field, which combines basic science and computing technology, has emerged as a third scientific methodology, following theories and experiments. This study aimed to identify factors and relationships that affect the continued use of the computational science and engineering (CSE) platform for its successful operation, utilization, and diffusion. To that end, the quality factors of the platform were derived by combining the information system success model and the technology acceptance model. These factors affected user satisfaction and intention to reuse through users' perceived usefulness and perceived ease of use of the platform. An empirical analysis was conducted through a questionnaire survey of 373 users of the EDISON platform, a representative CSE platform in Korea. The results revealed that all quality factors have a positive influence on perceived usefulness and perceived ease of use. Specifically, information quality has a significant influence on perceived ease of use, and system quality has a significant influence on perceived usefulness. Perceived ease of use has a greater impact on user satisfaction than perceived usefulness, and satisfaction affects intention to reuse. The results can contribute to the development of CSE platforms and the development strategy to expand the number of users.
\end{abstract}

Keywords: Computational Science and Engineering Platform, EDISON Platform, Information Systems Success Model, Technology Acceptance Model, Structural Equation Analysis

A preliminary version of this paper was presented at ICONI 2019, and was selected as an outstanding paper. This research was supported by the KISTI Program (No. K-20-L02-C05-S01), the EDISON Program through the National Research Foundation of Korea (NRF) (No. NRF-2011-0020576), and the NRF and the Center for Women In Science, Engineering and Technology (WISET-2020-190). 


\section{Introduction}

Computational science and engineering (CSE) is a new discipline consisting of the algorithms, software (SW), computers, and computing infrastructure to understand and solve complex problems in the science and engineering field [1,2]. In recent years, the CSE field has expanded because of rapid developments in computing performance as well as in networks and storage, accompanied by the increased use of high-performance computing (HPC) [3]. Therefore, cyber infrastructure-based simulations are widely used in various fields for education and research purposes [4].

Researchers in the CSE field typically develop simulation SW that runs on HPC resources, such as supercomputers or clusters. However, scientists who are not computational science engineers require much time and effort to build simulation SW for their research. Thus, there is a growing demand for simulation SW-centric platforms that support graphical user interfaces (GUIs) such as web portals, which will enable scientists to easily register, access, and run simulation SW [3].

The United States and countries in Europe have been pursuing CSE platform research and development. In particular, HUBZero, a platform of the nanoHUB service developed by Purdue University in 1995, is a representative CSE platform, currently being used in about 30 fields [5]. In Korea, the Korean Institute of Science and Technology Information (KISTI) developed and serviced the ED-ucation-research Integration through Simulation On the Net (EDISON) platform, with the support of the Ministry of Science and ICT, in order to support online education and research in the CSE field $[6,7,8]$.

Most research papers about CSE platforms focus on platform technology development and the application and utilization of platforms in various fields. However, there is a lack of research on factors affecting the use of CSE platforms from the user's perspective. For the successful operation of the platform, this study derived factors that affect the usage, examined the process of influence on user satisfaction, and finally the intention to reuse the platform. Based on this, the important factors of CSE platforms from the user's perspective can be identified to establish a development strategy for CSE platforms in the future.

This study developed a research model combining the factors in the technology acceptance model (TAM) to identify factors affecting the acceptance of new CSE technology and the information system success model (ISSM) to consider CSE platforms as a form of information system. The quality factors of CSE platforms were presented in the proposed research model, and how these factors affect the user's perceived ease of use and perceived usefulness was examined. In addition, the impact of these factors on user satisfaction and intention to reuse was identified $[9,10]$. In this study a survey of domestic users who have experience using the EDISON platform was conducted. After verifying the validity of the research model for the analysis of the survey results, the research model results were described, and the implications and future research directions were derived.

\section{Theoretical Background}

\subsection{The EDISON Project}

The EDISON project, which started in 2011, aims to secure original technology and foster convergent human resources by developing, utilizing, and diffusing simulation SW in the CSE 
field. The EDISON project has four main goals. First, it aims to conduct research and develop the EDISON platform based on cyber infrastructure to facilitate next-generation education and research. This is accomplished by providing science and engineering professors, students, researchers, and industrial personnel with simulation SW, data, educational materials, and research results that they can share or utilize. Second, it aims to build and service education and research web portals to provide a multidisciplinary problem-solving environment and strengthen the ecosystem through building and distributing high-quality contents that integrate the EDISON platform. Third, it aims to vitalize the user communities through the operation and cooperation of the primary and professional centers, and establish and support a voluntary, self-sustaining virtuous cycle system. Lastly, it seeks to expand and diversify the EDISON platform by working together with science and engineering educational institutions, research institutes, and industrial companies, and commercializing outstanding domestic simulation SW.

The EDISON project is operated through cooperation between the central center, which is the overall project organization, and the specialized centers, which are participating research institutes. The central center, i.e., KISTI, develops the EDISON platform, provides web-based user services, operates infrastructure for specialized fields, and supports performance expansion. The specialized centers derive improvement measures for the use of education and research and develop education and research simulation SW for each field. Currently, the specialized centers have been consist of seven fields, i.e., computational fluid dynamics, computational nanophysics, computational chemistry, computational structural dynamics, computer aided optimal design, computational medicine, urban environment. Fig. 1 presents an overview of the EDISON project.

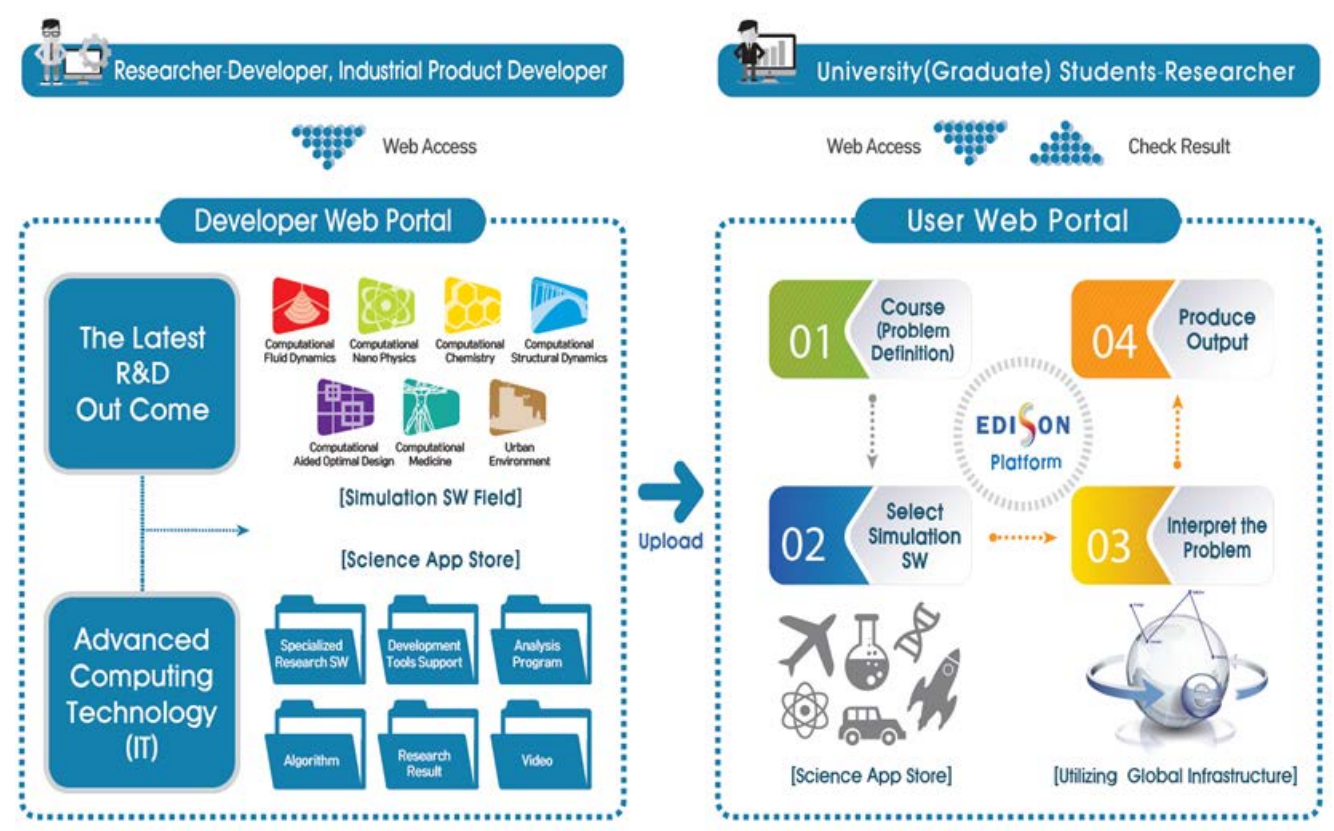

Fig. 1. EDISON project overview

As of December 2019, it consisted of approximately 900 simulation SW and 840 pieces of content, which are in use by approximately 70,000 cumulative people.

Kim et al. conducted research on how the EDISON platform affected user utilization [11]. 
They utilized the technology acceptance model (TAM) and the unified theory of acceptance and use of technology (UTAUT) and developed a model for user acceptance of the simulation SW installed on the EDISON platform to analyze the factors affecting the user [11]. However, this study analyzed users' satisfaction with the platform based only on their intention of using the information system

\subsection{Information System Success Model}

The basic purpose of information systems is to increase the rationality and efficiency of decision makers. This pertains to not only individuals but also organizations in which information systems are used to increase the organization's efficiency and productivity. Therefore, the benefits accruing to the user as a result of using the information systems in itself becomes a performance evaluation standard for the information systems [12].

Delone and McLean developed the information system success model (ISSM), which shows the relationships between six factors, i.e., system quality, information quality, usage level, user satisfaction, personal performance, and organizational performance, in 1992 [9]. They based their model on information systems and communication research, with the aim of providing a general definition of information system success that covers different points of view regarding information system evaluations.

They analyzed the success factors of information systems in 180 studies and structured the ISSM accordingly. Following Delone and McLean's study, many researchers presented the ISSM's limitations and proposed modified models for over a decade. In particular, there have been many changes in the use environment of information systems due to the rapid development of information technology. Therefore, Delone and McLean conducted research to complement their previous work and address its problems; they introduced a revised ISSM to measure the performance of e-commerce-related systems in 2003 (Fig. 2) [13].

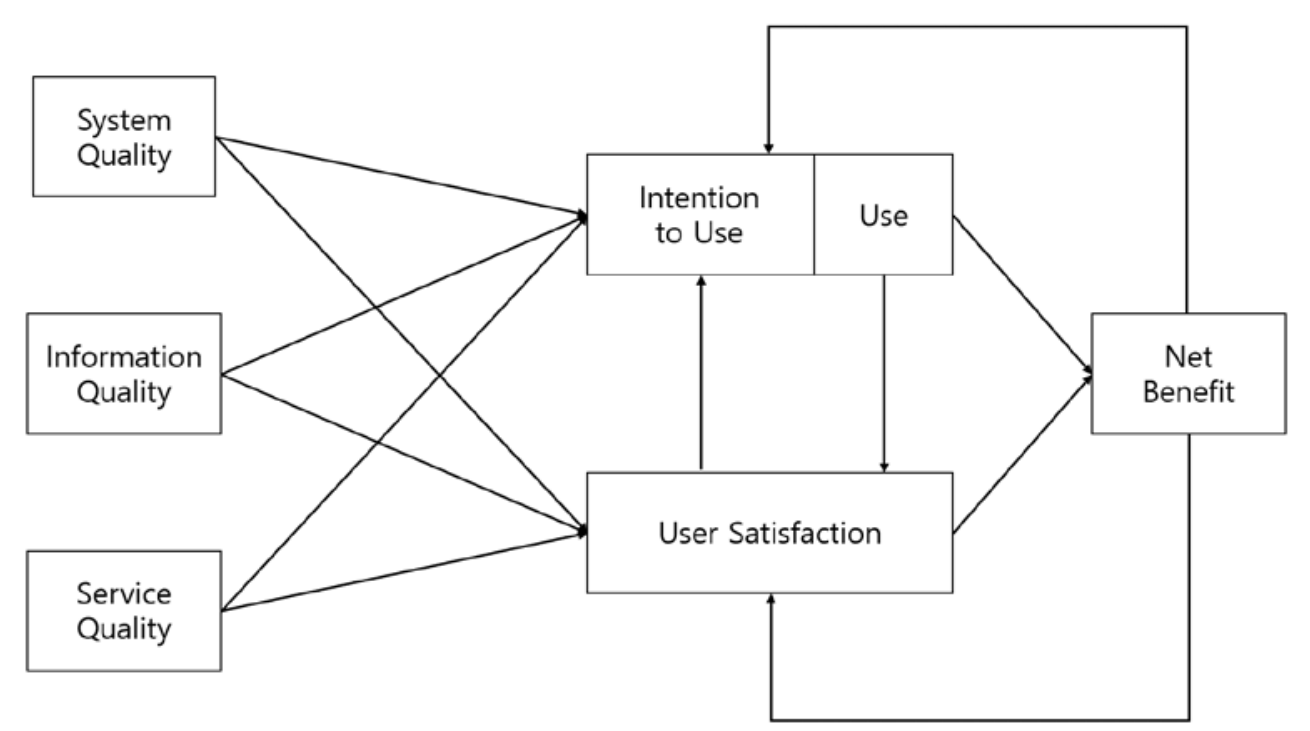

Fig. 2. Information System Success Model [13]

Delone and McLean's study is significant not only for categorizing information system success factors into six but also for its detailed description of how the factors impact the success of the information system. As such, it is still currently the basis for many studies 
related to the evaluation of information systems. In addition, the model that was released in 2003 evaluates a system from an informational, systemic, and service quality perspective, determining which characteristics affect user satisfaction and intention to use or reuse. Furthermore, net benefit occurs as a result of using the information system, and net benefit affects user satisfaction and the use of the information system. Even today, analyses are being conducted on factors that affect variables such as user satisfaction, by applying DeLone and McLean's ISSM to newly released information systems $[14,15,16]$.

\subsection{Technology Acceptance Model}

The technology acceptance model (TAM) is a simple, highly explanatory model that was developed to explain and predict the behavior of users utilizing various information technologies. Understanding why people accept or reject new information technologies is an important topic in new technology research [17].

Davis proposed TAM to make predictions about the acceptance of information technology, and many studies have been conducted since then based on the TAM [10]. TAM is theoretically based on the theory of reasoned action (TRA), which is a behavioral intention model known to be successful in explaining and predicting human behavior in a wide range of areas, and is also a good model for explaining behavioral factors of computer use in certain situations [18].

TAM is a user acceptance model for information technology and has been modified based on TRA. The purpose of TAM is to provide a theoretical basis for a measurement methodology on practical user acceptance regarding new technologies. (Fig. 3)

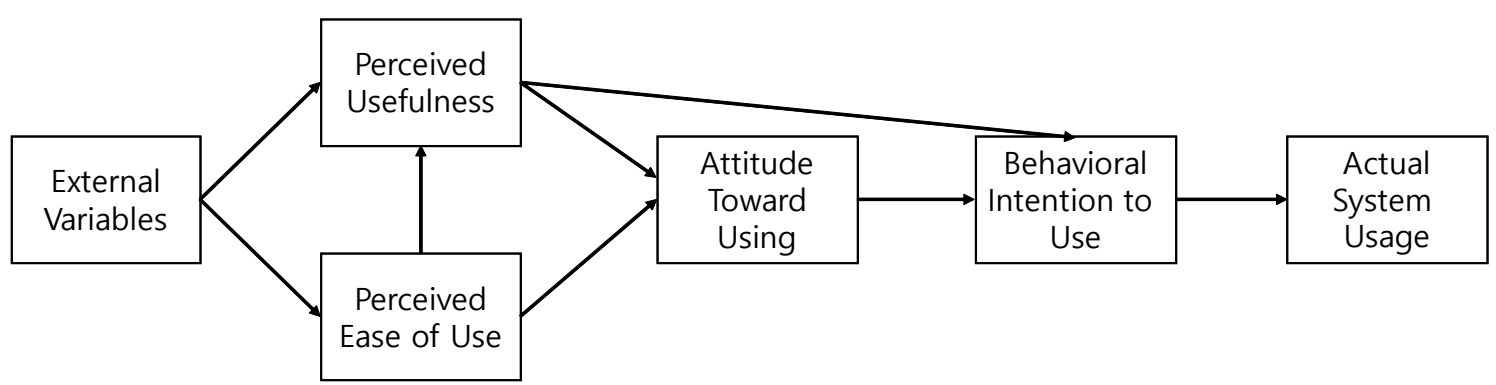

Fig. 3. Technology Acceptance Model [10]

In TAM, PU and perceived ease of use, which are affected by external variables, affect the attitude toward using the information technology. The resulting attitude affects the behavioral intention to use the information technology, and ultimately such behavioral intention affects actual use. In addition, PU, which is affected by the perceived ease of use and other external variables, has a direct impact on not only the attitude toward using but also on the behavioral intention to use the information technology [19, 20].

TAM is composed of four primary factors: PU, perceived ease of use, attitude toward using, and behavioral intention. PU can be defined as the degree to which it is believed that work performance can be increased by the use of a particular system [21]. It can be understood to mean that the user expects that his or her ability to perform a job or quality of life can be improved by the utilization of a specific information technology that could not be demonstrated by existing technology in terms of job productivity and efficiency [21]. It can be understood to mean that the user expects that his or her mental or physical efforts to acquire and use information technology or innovative products will be reduced. In other words, 
individual attitudes toward the adoption of information technology are determined when it is judged to be convenient or necessary to adopt new technologies or new systems [21]. Many studies use TAM to study the adoption of new information technologies and demonstrate the importance of PU and perceived ease of use [22,23,24].

\section{Analytical Method}

\subsection{Research Model}

The purpose of this study is to analyze the impacts of perceived usefulness, perceived ease of use, and quality factors derived from DeLone and McLean's ISSM on user satisfaction and the intention to reuse CSE platforms. The quality factors are derived from DeLone and McLean's ISSM to analyze user behavior related to a new information technology known as the CSE platform. According to TAM, the perceived usefulness and perceived ease of use ultimately affect the attitude toward using. The research model for this study is as shown in Fig. 4.

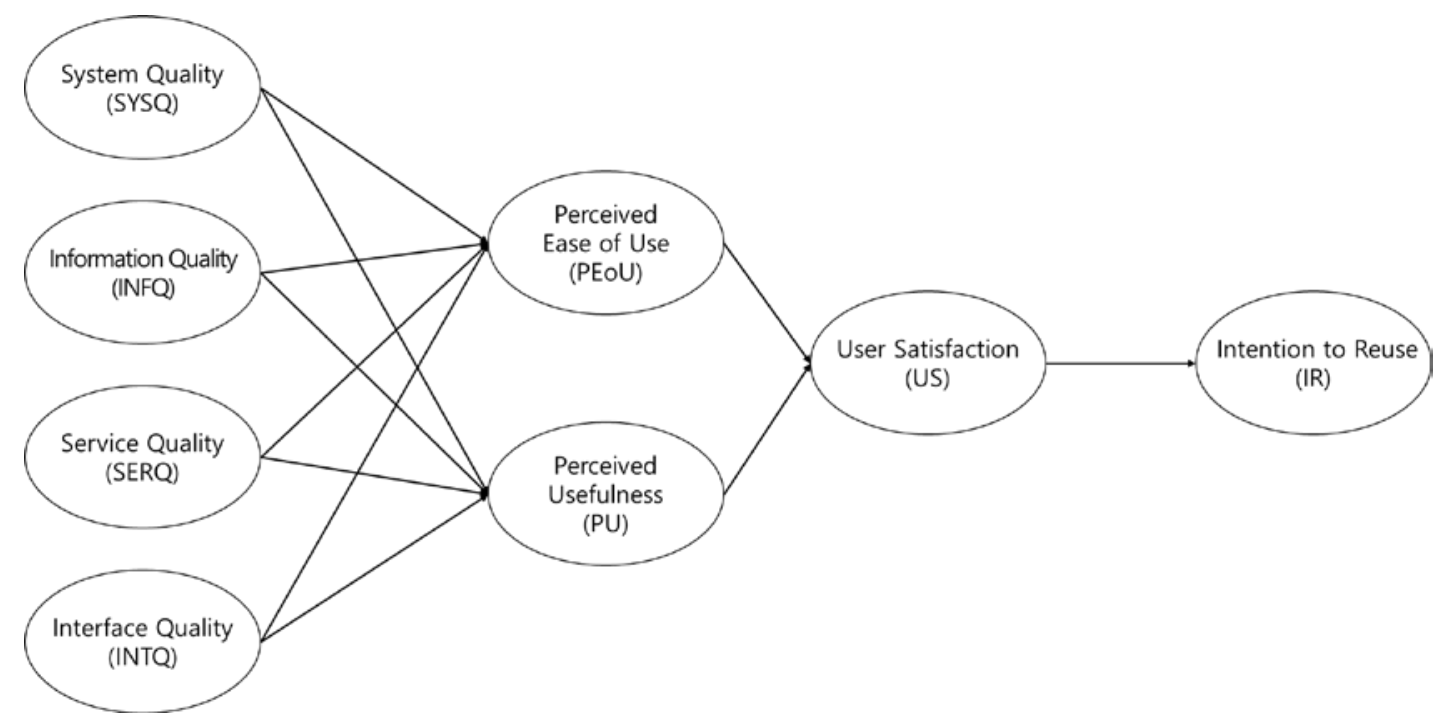

Fig. 4. Research model

\subsection{Research Hypotheses}

\subsubsection{Relationship between perceived ease of use and perceived usefulness, and information system quality factors}

Previous studies on information systems revealed that system quality (SYSQ) information quality (INFQ), and service quality (SERQ) have a positive influence on the overall utilization and user satisfaction (US) of the system, and also on perceived ease of use (PEoU) and perceived usefulness (PU). Ahn et al. found that system, information, and SERQ in online retailing affect users' PEoU and PU [25]. In a study of TAM for the introduction of medical information systems, Pai et al. confirmed that these factors affect the PEoU, and INFQ and SERQ affect the PU [26]. Seddon et al. conducted an empirical analysis on various information systems using DeLone and McLean's ISSM and found that SYSQ and INFQ 
eventually affect the PU [27].

Nguyen et al. examined factors affecting online customer loyalty in emerging countries and found that customer interface quality (INTQ) affected PEoU [28]. Mahatankoon et al. investigated factors affecting mobile device use and found that device INTQ affected PEoU [29]. Joo et al. confirmed the impact of cyber university's user interface elements on PEoU and PU [30]. Keat et al. found that interface design affects the PU on the TAM-based electronic commerce model [31]. Therefore, this study developed the following hypotheses based on the results of previous studies, including SYSQ, INFQ, SERQ suggested by ISSM, and INTQ.

[Hypothesis 1] Quality factors pertaining to CSE platforms will have a positive (+) effect on perceived ease of use.

[Hypothesis 2] Quality factors pertaining to CSE platforms will have a positive (+) effect on perceived usefulness.

\subsubsection{Relationship between perceived ease of use, perceived usefulness, and user satisfaction}

Rai et al. performed an empirical analysis on ISSM and confirmed that users' PEoU and PU affected US [32]. In addition, Roca et al. used an expanded TAM to demonstrate the continued use of e-Learning services and confirmed that PEoU and PU in e-Learning services also affect US [33]. Through this review of the previous studies, the following hypotheses were developed:

[Hypothesis 3] Perceived ease of use will have a positive (+) effect on user satisfaction.

[Hypothesis 4] Perceived usefulness will have a positive (+) effect on user satisfaction.

\subsubsection{Relationship between user satisfaction and intention to reuse}

Kettinger et al. conducted an empirical analysis on how quality factors of information system affected US and intention to reuse. As a result, it was found that US affected intention to reuse of information services [34]. Wang found that users' satisfaction affected their intention to reuse as a result of ISSM's empirical analysis on e-commerce system users [35]. Therefore, based on these previous findings, this study developed the following hypothesis:

[Hypothesis 5] User satisfaction will have a positive $(+)$ effect on intention to reuse CSE platforms.

\subsection{Operational Definition of Variables}

A survey was prepared and conducted based on the content defined by DeLone and McLean and Davis in order to determine whether the quality factors pertaining to CSE platforms affect user satisfaction and intention to reuse [36,19].

SYSQ is a characteristic of an information system and is a measure of its ease of use, system flexibility, system reliability and ease of learning, intuition, elaboration, and response time. SYSQ was measured by the quality of the simulation SW installed on the EDISON platform. INFQ is a desirable feature of the system output and is a measure of its fitness for 
purpose, understandability, accuracy, consistency, completeness, and fitness for use. INFQ was measured by the quality of content for the smooth use of the simulation SW on the EDISON platform. SERQ refers to the quality of support a system user can receive from the organization and the IT support staff that manage the information system, and is a measure of responsiveness, accuracy, reliability, and technical competence.

Based on previous studies, it can be concluded that user interface affects PU and PEoU [28,29,30,31,37]. Most users use the EDISON platform over the Web. A questionnaire of INTQ was constructed with five attributes (ease of use, ease of navigation, speed of access, ease of understanding, and ease of search) suitable for the web-based user interface based on previous studies. Survey questions were prepared based on these four attributes.

Perceived PEoU refers to the degree to which the user believes that they can easily use a particular system. Therefore, the survey for this study was prepared by considering the ease with which the user can use the EDISON platform, acquire information easily, and use the platform conveniently. PU is the degree to which the user believes that the use of a particular system will increase his or her performance. Therefore, the survey focused on the use of the platform for user learning, considering the fact that the EDISON platform is used mostly for education.

US measures the overall user satisfaction of the platform, including factors such as its functions and performance. And intention to reuse can be defined as the subjective possibility that the belief and attitude toward the product will be acted upon with regard to user intention to reuse or repurchase the product [38]. Based on this, the survey questions were prepared to also assess whether the user plans to continue to use the platform or not, and whether the user would be willing to recommend the EDISON platform to others. The survey questions for each variable were prepared as shown in Table 1.

Table 1. Survey questions.

\begin{tabular}{|c|c|}
\hline Factors & Survey questions \\
\hline SYSQ & $\begin{array}{ll}- & \text { The EDISON simulation is easy to execute. } \\
\text { - } & \text { The EDISON simulation is intuitive and easy to understand. } \\
\text { - } & \text { The EDISON simulation can be executed at any time. } \\
\text { - } & \text { The time required to complete the EDISON simulation is appropriate. } \\
\text { - } & \text { The execution of the EDISON simulation is stable. }\end{array}$ \\
\hline INFQ & $\begin{array}{ll}\text { - } & \text { The EDISON content helps me understand the simulation SW. } \\
\text { - } & \text { The EDISON content provides the latest information. } \\
\text { - } & \text { The EDISON content is clear and easy to understand. } \\
\text { - } & \text { The EDISON content is accurate and reliable. } \\
\text { - } & \text { The EDISON content provides specific and sufficient information. } \\
\text { - } & \text { The EDISON content is useful and valuable. } \\
\text { - } & \text { The EDISON simulation analysis results are accurate and reliable. }\end{array}$ \\
\hline SERQ & $\begin{array}{ll}- & \text { EDISON responds promptly to requests and inquiries. } \\
- & \text { EDISON has expert knowledge about requests and inquiries. } \\
- & \text { EDISON supports customized service for individual requests and inquiries. } \\
- & \text { EDISON provides accurate solutions to requests and inquiries. } \\
- & \text { EDISON provides bulletin boards and Q\&A services properly. }\end{array}$ \\
\hline INTQ & $\begin{array}{l}\text { - } \quad \text { The overall layout and composition of the EDISON Web portal is intuitive and } \\
\text { easy to grasp. } \\
\text { - } \quad \text { It is easy to move between contents and pages on the EDISON Web portal. } \\
\text { - } \\
\text { The EDISON Web portal facilitates access to desired information with a minimal } \\
\text { number of clicks. }\end{array}$ \\
\hline
\end{tabular}




\begin{tabular}{|c|c|}
\hline & $\begin{array}{l}\text { - } \quad \text { The menu names and structure of the EDISON Web portal are clear and easy to } \\
\text { understand. } \\
\text { - } \quad \text { Desired information can be easily found on the EDISON Web portal by searching. }\end{array}$ \\
\hline PEoU & $\begin{array}{ll}\text { - } & \text { The usage of the EDISON system is easy to learn. } \\
\text { - } & \text { The EDISON system helps me find the information I want easily. } \\
\text { - } & \text { It is easy to use the EDISON system at an expert level. } \\
\text { - } & \text { The EDISON system is generally convenient to use. }\end{array}$ \\
\hline PU & $\begin{array}{ll}\text { - } & \text { The EDISON system is useful for improving learning ability. } \\
\text { - } & \text { Learning goals can be easily achieved if the EDISON system is used. } \\
\text { - } & \text { The EDISON system is useful for effective learning. } \\
\text { - } & \text { Tasks can be completed quickly if the EDISON system is used. }\end{array}$ \\
\hline US & $\begin{array}{l}\text { - } \quad \text { I am generally satisfied with the EDISON system. } \\
\text { - } \quad \text { I am satisfied with the functions/performance provided by the EDISON system. } \\
\text { - } \quad \text { I am satisfied with the effort I have made to use the EDISON system. } \\
\text { - } \quad \text { I think using the EDISON system has helped me. }\end{array}$ \\
\hline IR & $\begin{array}{ll}\text { - } & \text { I will recommend using the EDISON system to other people. } \\
\text { - } & \text { I will continue to use the EDISON system. } \\
\text { - } & \text { I will take classes for using the EDISON system. } \\
\text { - } & \text { It will be beneficial for me to continue using the EDISON system in the future. }\end{array}$ \\
\hline
\end{tabular}

\section{Hypothesis Testing and Analysis Results}

\subsection{Data Collection and Analytical Method}

The survey for this study was conducted twice. The survey was administered to participants at the EDISON SW Challenge held in 2018 and 2019. A total of 373 responses were collected, and the missing values were analyzed by replacing them with the mean values of the series.

The SPSS and AMOS were used for hypothesis testing in this study. A frequency analysis was performed for the demographic analysis. In order to examine the impact of the quality factors regarding the EDISON platform on user satisfaction, a reliability analysis was conducted to evaluate the reliability of survey questions, and a factor analysis was used to evaluate the validity of survey questions. A correlation analysis was performed to evaluate the strength of the relationship between variables. Finally, a structural equation analysis was performed to identify the structural relationship between measured variables.

The demographic analysis of the sample was analyzed for variables such as gender, research fields, and use experience, and the results were shown in Table 2 below. First, among the 373 participants 270 respondents were men (72.4\%) and 99 respondents were women (26.5\%). By research fields, there were 47 respondents in computational nanophysics (12.6\%), 60 respondents in computational chemistry (16.1\%), 63 respondents in computational structural dynamics (16.9\%), 95 respondents in computer aided optimal design (25.5\%), 47 (12.6\%) respondents in computational medicine, and 61 (16.4\%) respondents in urban environment.

Half of the users have experienced simulation SW for less than 6 months (198, 53.7\%). A total of 62 (16.6\%) respondents have experienced more than 6 months and less than 1 year, 77 (20.6\%) respondents more than 1 year and less than 3 years, and 32 respondents (8.7\%) used for more than 3 years. 
Table 2. The demographic analysis

\begin{tabular}{|c|c|c|c|}
\hline \multicolumn{1}{|c|}{ Item } & Classification & Frequency & Percentage \\
\hline \hline \multirow{4}{*}{ Gender } & Male & 270 & 72.4 \\
\cline { 2 - 4 } & Female & 99 & 26.5 \\
\hline \multirow{4}{*}{ Research Fields } & Computational Nanophysics & 47 & 12.6 \\
\cline { 2 - 4 } & Computational Chemistry & 60 & 16.1 \\
\cline { 2 - 4 } & Computational Structural & 63 & 16.9 \\
\cline { 2 - 4 } & Dynamics & 95 & 25.5 \\
\cline { 2 - 4 } & Computer Aided Optimal Design & 47 & 12.6 \\
\cline { 2 - 4 } & Computational Medicine & 61 & 16.4 \\
\cline { 2 - 4 } & Urban Environment & 198 & 53.7 \\
\hline \multirow{3}{*}{$\begin{array}{c}\text { Experience using the } \\
\text { Simulation SW }\end{array}$} & $<6$ months & 62 & 16.6 \\
\cline { 2 - 4 } & 6 months 1 year & 77 & 20.6 \\
\cline { 2 - 4 } & 1 year 3 years & 32 & 8.7 \\
\cline { 2 - 4 } & $>3$ years & & \\
\hline
\end{tabular}

\subsection{Reliability Test}

Before testing the model and the hypotheses, a reliability test was performed to determine how consistently the variables were measured. Reliability refers to the variance of measured values when repeated measurements are made on the same concept. Cronbach's Alpha $(\alpha)$ is typically used to measure reliability, that is, how closely related a set of two or more predictor variables are as a group, with the confidence interval for the alpha coefficient ranging from 0 to 1 . In general, Cronbach's $\alpha$ coefficients are calculated for each variable to determine reliability. A Cronbach's alpha coefficient of 0.6 or more indicates an acceptable level of reliability [31].

A total of eight constructs were used in this study-SYSQ, INFQ, SERQ, INTQ, PU, PEoU, US and IR. The number of items for each construct are shown along with the reliability results in Table 3.

Table 3. Reliability analysis results

\begin{tabular}{|c|c|c|}
\hline Constructs & Items & Cronbach's $\boldsymbol{\alpha}$ \\
\hline \hline SYSQ & 5 & 0.867 \\
\hline INFQ & 7 & 0.873 \\
\hline SERQ & 5 & 0.950 \\
\hline INTQ & 5 & 0.921 \\
\hline PEoU & 4 & 0.929 \\
\hline PU & 4 & 0.930 \\
\hline US & 4 & 0.928 \\
\hline IR & 4 & 0.944 \\
\hline
\end{tabular}

The reliability analysis results showed that the Cronbach's $\alpha$ coefficient of all factors exceeded 0.8 , indicating that there was no problem with the reliability of the measured variables. 


\subsection{Validity Test}

Validity is a concept that shows how accurately a concept or attribute is measured and can be said to determine the exact extent to which a measurement tool for measuring a concept or characteristic accurately represents that characteristic or attribute. There are many validity tests, such as content validity and predictive validity, but, construct validity is most widely used in structural equation models.

Construct validity is a method of testing whether the measurement tool properly measures the concept that is intended to be measured, that is, the construct. It consists of convergent validity, discriminant validity, and legal validity. In this study, a confirmatory factor analysis was performed to verify these validities.

\subsubsection{Convergent validity}

Convergent validity, also known as congruent validity, is a method of evaluating the consistency of observation variables that measure latent variables. The methods for evaluating convergent validity include standardized factor loading and significance, average variance extracted (AVE), and construct reliability.

To secure convergent validity, the standardized factor loading should be at least 0.5 , ideally 0.7 or higher, and the construct reliability (C.R.) should also be at least 1.965. An AVE of at least 0.5 and a construct reliability of 0.7 or higher are acceptable criteria for the convergent validity to be confirmed [32,33]. In this study, all three methods were used to check for convergent validity, and the results are shown in Table 4.

Table 4. Convergent validity results

\begin{tabular}{|c|c|c|c|c|c|}
\hline \multirow[b]{2}{*}{ Constructs } & \multirow{2}{*}{$\begin{array}{l}\text { Measurement } \\
\text { Indicator }\end{array}$} & \multicolumn{4}{|c|}{ Validity Analysis } \\
\hline & & $\begin{array}{c}\text { Standardized } \\
\text { Factor Loading }\end{array}$ & T-value & $\begin{array}{l}\text { Construct } \\
\text { Reliability }\end{array}$ & AVE \\
\hline SYSQ & $\begin{array}{l}\text { SYSQ } 1 \\
\text { SYSQ } 2 \\
\text { SYSQ } 3 \\
\text { SYSQ } 4 \\
\text { SYSQ } 5\end{array}$ & $\begin{array}{l}0.860 \\
0.890 \\
0.710 \\
0.600 \\
0.660\end{array}$ & $\begin{array}{c}12.465 \\
12.697 \\
11.071 \\
\text { Fix } \\
10.463\end{array}$ & 0.733 & 0.360 \\
\hline INFQ & $\begin{array}{l}\text { INFQ } 1 \\
\text { INFQ } 2 \\
\text { INFQ } 3 \\
\text { INFQ } 5 \\
\text { INFQ } 6 \\
\text { INFQ } 7\end{array}$ & $\begin{array}{l}0.830 \\
0.790 \\
0.850 \\
0.840 \\
0.840 \\
0.710 \\
\end{array}$ & $\begin{array}{c}19.922 \\
18.563 \\
20.813 \\
\text { Fix } \\
20.221 \\
15.818\end{array}$ & 0.861 & 0.510 \\
\hline SERQ & $\begin{array}{l}\text { SERQ } 1 \\
\text { SERQ } 2 \\
\text { SERQ } 3 \\
\text { SERQ } 4 \\
\text { SERQ } 5\end{array}$ & $\begin{array}{l}0.850 \\
0.880 \\
0.940 \\
0.920 \\
0.860\end{array}$ & $\begin{array}{c}30.935 \\
26.769 \\
32.738 \\
\text { Fix } \\
25.679\end{array}$ & 0.907 & 0.660 \\
\hline INTQ & $\begin{array}{l}\text { INTQ } 1 \\
\text { INTQ } 2 \\
\text { INTQ } 3 \\
\text { INTQ } 4 \\
\text { INTQ } 5\end{array}$ & $\begin{array}{l}0.800 \\
0.860 \\
0.880 \\
0.890 \\
0.770\end{array}$ & $\begin{array}{c}20.150 \\
23.226 \\
23.926 \\
\text { Fix } \\
18.665\end{array}$ & 0.837 & 0.507 \\
\hline
\end{tabular}




\begin{tabular}{|c|c|c|c|c|c|}
\hline \multirow{3}{*}{ PEoU } & PEoU 1 & 0.900 & Fix & & \\
& PEoU 2 & 0.940 & 30.237 & 0.874 & 0.635 \\
& PEoU 3 & 0.920 & 28.675 & & \\
\hline \multirow{3}{*}{ PEU } & PEoU 4 & 0.770 & 19.730 & & \\
& PU 1 & 0.890 & 23.728 & & \\
& PU 2 & 0.880 & 23.244 & \multirow{2}{*}{0.861} & \\
& PU 3 & 0.870 & 22.703 & & \\
\hline \multirow{3}{*}{ US } & PU 4 & 0.870 & Fix & & \\
& US 1 & 0.880 & Fix & & \\
& US 2 & 0.870 & 24.305 & 0.859 & \\
& US 3 & 0.850 & 22.946 & & \\
\hline & US 4 & 0.870 & 23.866 & & \\
\hline
\end{tabular}

As a result of the analysis, "INFQ 4" of information quality, which showed a low standardized factor loading $(\lambda=0.412)$, was excluded.

In addition, the AVE value of SYSQ was 0.360, which was below the acceptable criterion of 0.5 , but the construct reliability and the standardized factor loading were higher than 0.7 and 0.5 , respectively, indicating that there was no problem with convergent validity; thus, it was used as-is in the analysis.

\subsubsection{Discriminant validity}

Discriminant validity checks whether there is no overlap or similarity between two or more latent variables. Discriminant validity can be verified by selecting pairs of two constructs and comparing the chi-square difference between the non-constrained model (free model) with free correlations between two constructs, and the constrained model in which the covariance between the two constructs is set to 1 . If the chi-square difference between the two models is significant ( $\chi^{2}=3.84$ or more), the discriminant validity of the correlation between variables is assessed to be secured [33]. The correlation between latent variables through a confirmatory factor analysis was as displayed in Table 5.

Table 5. Correlation between constructs

\begin{tabular}{|c|c|c|c|c|c|c|c|c|c|c|}
\hline & Mean & SD (б) & $\mathbf{1}$ & $\mathbf{2}$ & $\mathbf{3}$ & $\mathbf{4}$ & $\mathbf{5}$ & $\mathbf{6}$ & $\mathbf{7}$ & $\mathbf{8}$ \\
\hline 1. SYSQ & 4.73 & 1.23 & 1 & & & & & & & \\
\hline 2. INFQ & 4.91 & 1.16 & $.755^{* *}$ & 1 & & & & & & \\
\hline 3. SERQ & 5.12 & 1.27 & $.607^{* *}$ & $.684^{* *}$ & 1 & & & & & \\
\hline 4. INTQ & 4.68 & 1.33 & $.571^{* *}$ & $.620^{* *}$ & $.596^{* *}$ & 1 & & & & \\
\hline 5. PEOU & 5.02 & 1.31 & $.709^{* *}$ & $.736^{* *}$ & $.636^{* *}$ & $.667^{* *}$ & 1 & & & \\
\hline 6. PU & 4.86 & 1.28 & $.712^{* *}$ & $.778^{* *}$ & $.652^{* *}$ & $.641^{* *}$ & $.824^{* *}$ & 1 & & \\
\hline 7. US & 4.92 & 1.3 & $.699^{* *}$ & $.788^{* *}$ & $.605^{* *}$ & $.680^{* *}$ & $.787^{* *}$ & $.818^{* *}$ & 1 & \\
\hline 8. IR & 4.82 & 1.42 & $.678^{* *}$ & $.777^{* *}$ & $.584^{* *}$ & $.656^{* *}$ & $.723^{* *}$ & $.813^{* *}$ & $.867^{* *}$ & 1 \\
\hline
\end{tabular}

Correlation is significant at the 0.01 level (two-tailed test) 
Because examining all the pairs of constructs is not easy and the correlation coefficients are high, an examination of the conceptually similar PEoU and PU is as follows: $\chi^{2}=1746.4$, $\mathrm{df}=601$ for the non-constrained model and $\chi^{2}=1756.3$, $\mathrm{df}=602$ for the constrained model, which constrained the covariance between the PEoU and the PU to be $1 . \Delta \chi^{2}=9.9$ showed a significant difference between the two models, indicating discriminant validity (Table 6).

Table 6. The chi-square difference between the unconstrained model and constrained model

\begin{tabular}{|c|c|c|c|}
\hline & $\chi^{\mathbf{2}}$ & $\begin{array}{c}\text { degree of } \\
\text { freedom (df) }\end{array}$ & $\Delta \chi^{\mathbf{2} / \mathbf{d f}}$ \\
\hline \hline Unconstrained model & 1746.4 & 601 & \\
\hline Constrained model & 1756.3 & 602 & $9.9 / 1$ \\
\hline
\end{tabular}

\subsubsection{Legal validity}

Legal validity is concerned with the direction between the constructs and involves checking whether the relationship between the variables is positive or not in Table 5. In this study, the relationships between all the constructs had been assumed to be positive, and indeed, the relationships between all variables were shown to be positive, as demonstrated in the correlation table, thereby confirming legal validity [34].

\subsection{Hypothesis Testing Results and Implications}

\subsubsection{Path analysis for research model}

Reliability and validity of constructs in the research model were established on the above tests. Thus the hypotheses were tested using AMOS to make direct comparisons between coefficients in the model. In the structural equation analysis, there is no absolute criterion for the model fit. Sometimes, studies require that both CFI and GFI numbers be above .90, while in other cases, even if the numbers are above .80 , the measurement model is considered to be of value [35]. The results are shown in Table 7 and Table 8.

Table 7. Model fit index

\begin{tabular}{|c|c|c|c|}
\multicolumn{1}{|c}{ Table 7. Model fit index } \\
\hline \hline $\begin{array}{c}\text { Research } \\
\text { model }\end{array}$ & 1880.916 & df & p \\
\hline
\end{tabular}

Table 8. Model fit index

\begin{tabular}{|c|c|c|c|c|c|c|}
\hline & CFI & NFI & GFI & AGFI & RMSEA & SRMR \\
\hline \hline $\begin{array}{c}\text { Goodness of } \\
\text { fit index }\end{array}$ & .913 & .877 & .764 & .729 & .075 & .0467 \\
\hline $\begin{array}{c}\text { Acceptance } \\
\text { criteria }\end{array}$ & $>.9$ & $>.9$ & $>.9$ & $>.9$ & $<.1$ & $<.05$ \\
\hline
\end{tabular}

The goodness-of-fits for the research model in this study were: $\mathrm{CFI}=0.913$ and RMSEA $=$ 0.075 with NFI, CFI, RMSEA, and SRMR as shown above. Thus, the research model was considered to be fit for analysis without a modified model and the results were shown in Fig. 5 [34]. 


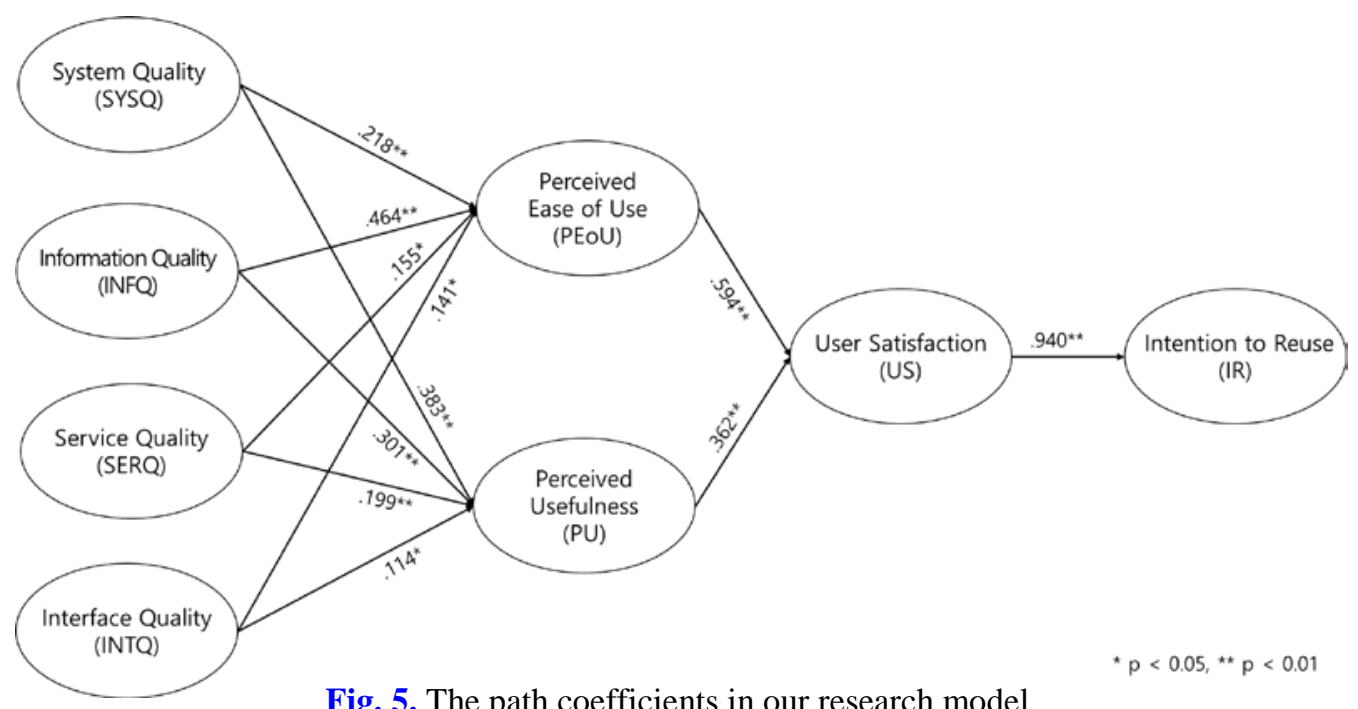

Fig. 5. The path coefficients in our research model

The analysis results of all path coefficients in the research model were significant. The quality factors of the CSE platform were all found to have positive effects on PEoU and PU. In addition, it was found that both PEoU and PU affected US and then positively affected the intention to reuse the CSE platform.

Based on Fig. 5, from the result of standardized coefficients, it was found that the INFQ of the platform (0.464) had the most significant impact on PEoU, and the SYSQ (0.383) had the most significant impact on PU. It was found that both PEoU and PU had positive impacts on US, and PEoU (0.594) had a more significant impact than PU (0.362). In addition, it was found that US (0.940) significantly impacted the intention to reuse the CSE platform.

\subsubsection{Hypothesis test results}

Table 9 shows the results of the path coefficients for the hypothesis verification of the research model.

Table 9. Path coefficient results

\begin{tabular}{|c|c|c|c|c|c|c|c|c|}
\hline \multicolumn{3}{|c|}{ Path (hypothesis) } & $\begin{array}{c}\text { Standardized } \\
\text { Coefficient }\end{array}$ & $\begin{array}{c}\text { Non- } \\
\text { standardized }\end{array}$ & S.E & C.R & $\mathbf{p}$ & $\begin{array}{l}\text { Hypothesis } \\
\text { Adopted or }\end{array}$ \\
\hline SYSQ & \multirow{4}{*}{$\rightarrow$} & \multirow{4}{*}{ PEoU } & .218 & 2.285 & $\begin{array}{l}.085 \\
\end{array}$ & 3.359 & "** & Accepted \\
\hline INFQ & & & .464 & .475 & .077 & 6.174 & $* *$ & Accepted \\
\hline SERQ & & & .155 & .148 & .045 & 3.270 & $.001^{*}$ & Accepted \\
\hline INTQ & & & .141 & .128 & .040 & 3.209 & $.001^{*}$ & Accepted \\
\hline SYSQ & \multirow{4}{*}{$\rightarrow$} & \multirow{4}{*}{ PU } & .383 & .535 & .099 & 5.419 & $* *$ & Accepted \\
\hline INFQ & & & .301 & .329 & .082 & 3.999 & $* *$ & Accepted \\
\hline SERQ & & & .114 & .116 & .049 & 2.352 & $.019^{*}$ & Accepted \\
\hline INTQ & & & .199 & .195 & .044 & 4.426 & $* *$ & Accepted \\
\hline PEoU & \multirow{2}{*}{$\rightarrow$} & \multirow{2}{*}{ US } & .594 & .628 & .055 & 11.464 & $* *$ & Accepted \\
\hline $\mathrm{PU}$ & & & .362 & .358 & .049 & 7.276 & $* *$ & Accepted \\
\hline US & $\rightarrow$ & IR & .940 & .990 & .042 & 23.578 & $* *$ & Accepted \\
\hline
\end{tabular}

${ }^{*} \mathrm{p}<0.05,{ }^{* *} \mathrm{p}<0.01$ 
First, hypothesis 1 regarding the relationship of each quality factor to PEoU was verified. The path coefficient of SYSQ and PEoU was $0.218(\mathrm{t}=3.359)$, INFQ was $0.464(\mathrm{t}=6.174)$, INTQ was $0.141(\mathrm{t}=3.209)$, and SERQ was $0.155(\mathrm{t}=3.270)$. That is, hypothesis 1 was adopted because all factors had a statistically significant effect at the 0.01 level. The results that system quality, information quality, and service quality affect PEoU are the same as those of Ahn et al. and Pai et al. [25, 26]. In addition, the finding that interface quality affects perceived ease of use is the same as those of Joo et al. and Nguyen et al.[30,28].

As such, it was confirmed that all the quality factors of the CSE platform contribute to making it easier for users to use the platform. Comparing the path coefficients of other quality factors, the path coefficient of information quality is the highest and has the greatest influence on PEoU. This is related to the frequency analysis of survey users; $53 \%$ of users had less than 6 months of experience using the CSE platform, and 70\% had less than 1 year of experience. The CSE platform provides users with a variety of information that allows them to use simulation easily. It can be interpreted as a result that the information helps a number of users who have little experience with the CSE platform.

Second, hypothesis 2 regarding the relationship of each quality factor to PU was verified. The path coefficient of SYSQ and PU was $0.383(t=5.419)$, INFQ was 0.301( $\mathrm{t}=3.999)$ INTQ was $0.199(\mathrm{t}=4.426)$, and had a statistically significant effect at the 0.01 level. The path coefficient of SERQ was $0.114(\mathrm{t}=2.352)$ and had a statistically positive effect at the 0.05 significance level. The results that system quality, information quality, and service quality affect PU are the same those of Ahn et al. and Pai et al.[25,26]. The finding that user interface affects perceived usefulness is the same as those of Joo et al. and Keat et al. [30,31].

It was confirmed that all quality factors of the CSE platform contribute for users to use simulation through CSE platforms. The path coefficient showed that the quality of the system significantly affected perceived usefulness compared to the three other qualities. The purpose of CSE platforms is to provide an environment in which scientists and engineers can easily register, access, and execute simulation SW [3]. Therefore, the analysis results confirmed that the core function of the CSE platform functions properly.

Hypotheses 3 and 4 were adopted, as the coefficient of pathways for PEoU and US was $0.594(\mathrm{t}=11.464)$ and the coefficient of pathways for PU and USwas $0.362(\mathrm{t}=7.276)$ all having statistically significant effects at a significance level of the 0.01 . This confirmed that, as with the studies of Lai et al. and Juan Carlos Roca et al., the perceived ease of use and perceived usefulness of users affect user satisfaction [32,33].

Comparing the path coefficients of PU and PEoU in the CSE platform, PEoU had a greater impact than PU. However, Rai et al. revealed similar effects of PEoU and PU on US [32], while Roca et al. found that PU has a greater influence on US than PEoU [33]. Nguyen et al. and Ramkumar et al. found that PEoU did not have a direct effective influence on US $[28,44]$. Traditionally, simulation users used an unfriendly user interface, CLI (Command Line Interface), to perform simulations. However, through the web interface provided by CSE platforms, it can be interpreted that users were more satisfied with the environment in which simulations could more be easily executed than the CLI environment. Thus, the results of the analysis differed from those of previous studies.

Finally, the path coefficient for US and IR was $0.940(\mathrm{t}=23.578)$, which was found to have a statistically significant effect at the 0.01 level, and hypothesis 5 was adopted. As in Kettinger et al. and Wang, the user satisfaction level of those using the services of the CSE platform was found to eventually affect the reuse of the platform $[34,35]$.

In summary, it is necessary to improve user satisfaction affecting the user's intention to reuse CSE platforms. To this end, efforts must be made to improve platform quality factors 
that affect perceived ease of use and perceived usefulness. In particular, system quality and information quality appeared to be the primary quality factors of CSE platforms, and it was confirmed that perceived ease of use had a greater influence on user satisfaction than perceived usefulness. Therefore, for the successful operation of CSE platforms, efforts should be made to improve quality factors of the platform by providing information that makes it easy for users to use CSE platforms while making it easy and reliable to run simulations.

\section{Conclusion}

This study derived the factors of CSE platforms that affect the use of the platform for the successful and continuous operation of the platform and examined user satisfaction and its influence on intention to reuse. Therefore, the quality factors were derived based on the ISSM and the TAM by adding the quality of the interface reflecting the characteristics of the platform being served on the Web. Then, adding the variables of perceived ease of use and perceived usefulness, those factors were used to develop a research model that demonstrates the factors that affect user satisfaction and intention to reuse.

This study conducted empirical analysis of users of the EDISON platform, the representative CSE platform in Korea. The results revealed that system, information, interface, and service quality all affected the perceived ease of use and perceived usefulness. In particular, it was found that information quality had a significant influence on perceived ease of use, and system quality had a significant influence on perceived usefulness. This result showed that CSE platforms fulfilled its purpose, which provided an environment in which scientists easily performed simulations. In addition, both perceived usefulness and perceived ease of use affected user satisfaction, and the latter had a greater impact on user satisfaction than the former. This means that users were more satisfied because they were able to run simulations easily through the Web interface provided by CSE platforms compared to traditional CLI-based ones. Finally, user satisfaction was shown to have a significant impact on intention to reuse. This confirms that the proposed research model is suitable for analyzing the intention to reuse CSE platforms.

The implications of the results are that user satisfaction is critical for users to continue to use CSE platforms. The quality factors that affected user satisfaction were the information quality, which has a significant impact on perceived ease of use, and the system quality, which had a significant influence on perceived usefulness. In addition, as all other quality factors eventually affected user satisfaction and intention to reuse, improvement strategies in CSE platforms should be developed to improve quality in future, and the primary quality factors, improving information and system quality, should be considered first.

This study had the limitation that the survey respondents were only participants in the EDISON SW Challenges, which represented only a small proportion of the total number of users of the EDISON platform. The EDISON platform is currently being utilized by about 10,000 users a year, of which a large majority use the EDISON platform for undergraduate classes. Therefore, a further research would be needed to generalize the results on the usage of the EDISON platform.

In addition, one of the goals of the EDISON project is to foster computational science engineers to result in an expansion of computational science and engineering in Korea. Consequently, it is expected to contribute to increasing the number of HPC and supercomputer users in Korea. To ensure that this goal is met, For this goal, it is necessary to study that the learning transfer of CSE platforms user occurs. To this end, future research is needed to analyze which factors affect the user's learning transfer through empirical analysis. Such a 
study is expected to show whether the investments that have been made in the EDISON project for ten years contribute to the expansion of CSE and the HPC ecosystem in Korea.

\section{References}

[1] G. H. Golub, and J. M. Ortega, Scientific computing and differential equations, An introduction to numerical methods, Academic Press, Boston, 1992.

[2] E. Gallopoulos, and A. Sameh, "CSE: content and product," IEEE Computational Science and Engineering, vol. 4, no. 2, pp. 39-43, 1997. Article (CrossRef Link).

[3] Y.K. Suh, H. Ryu, H. G. Kim, and K. W. Cho, "EDISON: A Web-Based HPC Simulation Execution Framework for Large-Scale Scientific Computing Software," in Proc. of 2016 16th IEEE/ACM International Symposium on Cluster, Cloud and Grid Computing, Cartagena, pp. 608-612, 2016. Article (CrossRef Link).

[4] J. H. Gwak, "An introduction to a Computational Science Cooperative Course,” Natural Science, vol. 17, page 227, 2004.

[5] M. McLennan and R. Kennell, "HUBzero: A Platform for Dissemination and Collaboration in Computational Science and Engineering," Computing in Science \& engineering, 2010.

[6] J. Ma, J. Ruth Lee, K.W. Cho, and M.J. Park, "Design and Implementation of Information Management Tools for the EDISON Open Platform," KSII Transactions on Internet and Information Systems, vol. 11, no. 2, pp. 1089-1104, 2017. Article (CrossRef Link).

[7] H. Ryu, J. L. Yu, D.S. Jin, J.H. Lee, Duk-Yun Nam, Jong-Suk Ruth Lee, Kumwon Cho, Heejung Byun, and Ok-Hwan Byeon, "EDISON Science Gateway: A Cyber-Environment for Domain-Neutral Scientific Computing," IEICE Transactions, vol. E97-D, no.8, pp. 1953-1964, 2014. Article (CrossRef Link).

[8] S. Park, D. Jin, J. R. Lee, K. W. Cho and K. Lee, "Intelligent u-Learning and Research Environment for Computational Science on Mobile Device," KSII Transactions on Internet and Information Systems, vol. 8, no. 2, pp. 707-720, 2014. Article (CrossRef Link).

[9] W. H. DeLone and E. R. McLean, "Information Systems Success: The Quest for the Dependent Variable," Information System Research, vol. 3, no. 1, pp. 1-95, 1992. Article (CrossRef Link).

[10] F. D. Davis, A Technology Acceptance Model for Empirically Testing New End-User Information Systems: Theory and Results, Sloan School of Management, Massachusetts Institute of Technology, 1986.

[11] N. Kim, N. R. On, J. S. Ruth Lee1, D. Nam, K.W. Cho, K. T. Choe and J. Yu, “An empirical analysis of the user acceptance of computer simulations utilized for higher education in science and engineering," ICIC Express Letters, Part B: Applications, vol. 6, no. 4, pp. 1197-1203, January 2015.

[12] G. Song, G. Kim, and H. Yoo, "The Effect of Weather Information System Quality Factor on User Satisfaction and Business Performance," Journal of the Korean Society for Quality Management, vol. 45, no. 1, pp .093-116, 2017. Article (CrossRef Link).

[13] W. H. DeLone and E. R. McLean, "The DeLone and McLean Model of Information Systems Success: A Ten-Year Update," Journal of Management Information Systems, vol. 19, no. 4, pp. 9-30, 2003. Article (CrossRef Link).

[14] H. H. Cho, "Study on Influence of Perceived Quality Factor of Smartphone on Satisfaction \& Continued Use Intention - From the Standpoint of Updated Delone \& McLean`s Information System Success Model -," Entrue Journal of Information Technology, vol. 11, no. 2, pp. 167-180, 2012.

[15] S. H. Ha, S. H. Joo, "Internet banking system quality and its impact on user satisfaction and service loyalty: banking services perspective,” The Journal of Internet Electronic Commerce Research vol. 10, no. 1, pp. 173-195, 2010.

[16] B. G. Kim and I. K. Yoon, "Factors Affecting the Quality of Social Network Service on User Satisfaction and Continuance Usage Intention," Journal of Information Technology Applications \& Management, vol. 21, no. 1, pp. 35-51, 2014. 
[17] D. L. Swanson, "Gratifications seeking, media exposure and audience interpretations: Some directions for research,” Journal of Broadcasting and Electronic Media, vol. 31, no. 3, pp. 237-254. 1987. Article (CrossRef Link).

[18] F.D. Davis, R. P. Bagozzi and P. R. Warshaw, ”User Acceptance of Computer Technology: A Comparison of Two Theoretical Models," Management Science, vol. 35, no. 8, pp. 982-1028, 1989. Article (CrossRef Link).

[19] F. D. Davis, "Perceived Usefulness, Perceived Ease of Use, and User Acceptance of Information Technology,” MIS Quarterly, vol. 13, no. 3, pp. 319-340, 1989. Article (CrossRef Link).

[20] S. Taylor and P. A. Todd, "Understanding information technology usage: A test of competing models," Information Systems Research, vol. 6, no. 2, pp. 85-188, 1995. Article (CrossRef Link).

[21] J. C. Oh, S. J. Yoon and Y. Wu, "A Study on Factors of Intention toward Using Mobile Internet Service : Revised TRAM," Journal of Korea Service Management Society, vol. 11, no. 5, pp. 127-148, 2010. Article (CrossRef Link).

[22] T. Y. Yoon, "A Study of Reuse Intention of an Airline Mobile App Using The Technology Acceptance Model," Journal of Hotel \& Resort, vol. 15, no.2, pp. 351-369, 2016.

[23] W. K. Lee and J. Kwon, "An Analysis of the Relationships between the Technology Acceptance Model and Switching Costs," Journal of the Korean Operations Research and Management Science Society, vol. 2, no. 1, pp. 89-104, 2012. Article (CrossRef Link).

[24] D. G. Youn, "A Study of Affecting Factors to Learner's Satisfaction in Business Cyber Education," The e-Business Studies, vol. 13, no. 2, pp. 49-69, 2012. Article (CrossRef Link).

[25] T. Ahn, S. Ryu, and I. Han, The impact of Web quality and playfulness on user acceptance of online retailing, Information \& Management, Vol. 44, no. 3, pp.263-275, 2007. Article (CrossRef Link).

[26] F. Pai, and K. Huang, "Applying the Technology Acceptance Model to the introduction of healthcare information systems," Technological Forecasting and Social Change, vol. 78, no. 4, pp.650- 660, 2011. Article (CrossRef Link).

[27] P Seddon, and M.Y. Kiew, “A Partial Test and Development of Delone and Mclean's Model of IS Success," Australasian Journal of Information Systems, vol.4, no.1, 1996. Article (CrossRef Link).

[28] T. T. M. Nguyen, Y. Takahashi, and N. P. Tuan, "Technology acceptance model and the paths to online customer loyalty in an emerging market," Trziste, vol. 25, no.2, pp. 231-248, 2013

[29] P. Mahatanankoon, H. J. Wen, and B. B. L. Lim, "Evaluating the technological characteristics and trust affecting mobile device usage," International Journal of Mobile Communications, vol. 4, no. 6, pp.662-681, 2006. Article (CrossRef Link).

[30] Y. Joo, H.W. Lee, and Y. Ham, "Integrating user interface and personal innovativeness into the TAM for mobile learning in Cyber University" Journal of Computing in Higher Education, vol. 26, no. 2, pp. 143-158, 2014. Article (CrossRef Link).

[31] T.K. Keat, and A. Mohan, "Integration of TAM based electronic commerce model for trust," Journal of American Academy of Business, vol. 5, No.1, pp.404-410, 2004

[32] A. Rai, S. Lang, and R. Welker, "Assessing the Validity of IS Success Models: An Empirical Test and Theoretical Analysis," Information Systems Research, vol. 13, no.1, pp. iii-111, 2002. Article (CrossRef Link).

[33] J. C. Roca, C. Chiu, F. J. Martinez, "Understanding e-learning continuance intention: An extension of the Technology Acceptance Model," International Journal of Human-Computer Studies, vol. 64, no. 8, pp. 683-696, 2006. Article (CrossRef Link).

[34] W.J. Kettinger, S.H. Park, and J. Smith, "Understanding the consequences of information systems service quality on IS service reuse,” Information \& Management, vol.46, no.6, pp.335-341, 2009. Article (CrossRef Link).

[35] Y.S.Wang, "Assessing e-commerce systems success: A respecification and validation of the DeLone and McLean model of IS success," Information Systems Journal, vol.18, no.5, pp.529-557, 2008. Article (CrossRef Link).

[36] W. H. DeLone and E. R. McLean, "Information Systems Success Measurement," Foundations and Trends in Information Systems, vol. 2, no. 1, pp 1-116, 2016. Article (CrossRef Link). 
[37] V. Cho, T.C.E. Cheng, and W.M.J. Lai, "The role of perceived user-interface design in continued usage intention of self-paced e-learning tools,” Computers \& Education, vol. 53, no 2, pp. 216-227, 2009. Article (CrossRef Link).

[38] J. F. Engel and R. D. Blackwell, Consumer Behavior, 4th edition, The Dryden Press, Hinsdae, Illinois, p.321-326, 1982.

[39] J Hair, W Black, B Babin and R Anderson, Multivariate Data Analysis, Pearson Prentice Hall, 2010.

[40] W. W. Chin, “The partial least squares approach for structural equation modeling,” Modern methods for business research, pp. 295-336, 1998.

[41] J. P. Yu, Gujobangjeongsigui gaenyeomgwa ihae, Hannarae Academy, Seoul, 2012.

[42] C. Fornell and D. F. Larcker, "Evaluating Structural Equation Models with Unobservable Variables and Measurement Error,” Journal of Marketing Research, Vol. 18, No. 1, pp. 39-50, February, 1981. Article (CrossRef Link).

[43] P. Barrett, “Structural equation modelling: Adjudging model fit,” Personality and Individual differences, vol. 42, no. 5, pp. 815-824, 2007. Article (CrossRef Link).

[44] M. Ramkumar, T. Schoenherr, S. M. Wagner, and M. Jenamani, “Q-TAM: A quality technology acceptance model for predicting organizational buyers' continuance intentions for e-procurement services,” International Journal of Production Economics, vol. 216, pp. 333-348, 2019. Article (CrossRef Link). 


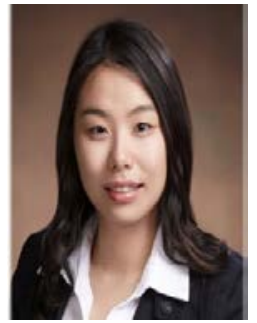

Noori On received her bachelor's degree and master's degree in management at Korea University of Technology and Education (KOREATECH) in 2007 and 2010, respectively. She worked as a researcher at Korea Institute of Science and Technology Information (KISTI) for five years since 2010 and took part in making policies and planning for National Supercomputing. She has served as a researcher at KISTI since 2018. At present, she participates in the EDISON (ED-ucation-research Integration through Simulation On the Net) project, which is a web-based simulation service for education and research. She is interested in policies for HPC and computational science and engineering.

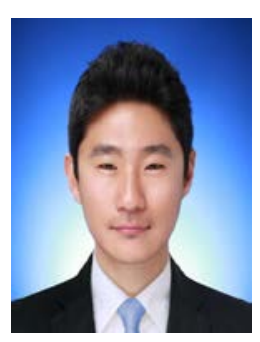

Gi-Myeong Ryu is a researcher at the Center for Computational Science Platform of Korea Institute of Science and Technology Information (KISTI), South Korea. He received BEng and MEng degrees in Aerospace Engineering from Chungnam National University in 2013 and 2016, respectively. At present, he participates in the EDISON (ED-ucation-research Integration through Simulation On the Net) project, which is a web-based simulation service for education and research. His research interests are computational science, aerospace, and fluid analysis.

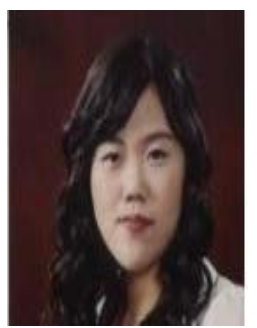

Myoung-Ju Koh received the B.S. degree in Systems Management Engineering from Sungkyunkwan University (SKKU), in 2005 and an M.S degree and a Ph. D. degree in Industrial Engineering from SKKU in 2007 and 2014, respectively. She worked in the Science and Technology Policy Institute (STEPI) for six years from 2009. She has been serving as a Senior Researcher at Korea Institute of Science and Technology Information (KISTI) since 2015. She researches research policy and the strategic management of the Korea National Supercomputing Center.

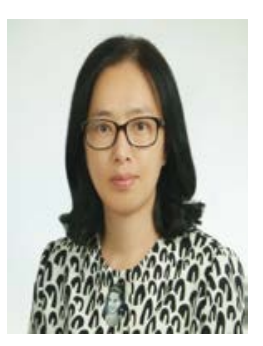

Jongsuk Ruth Lee received her Ph.D. in Computer Science from the University of Canterbury, New Zealand. She is a principal researcher at the National Institute of Supercomputing and Networking, Korea Institute of Science and Technology Information (KISTI), and an adjunct faculty at the University of Science \& Technology of Korea. Her research interests are smart learning, parallel/distributed computing and simulation, and big data handling.

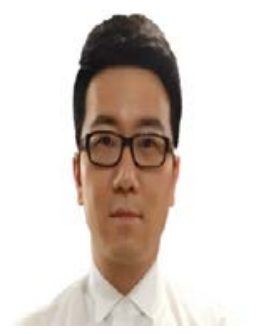

Nam-Gyu Kim obtained his bachelor's degree and master's degree in computer science and engineering at Chung-Ang University in 2000 and 2002, respectively. He received his $\mathrm{Ph}$. D. in Management of Technology from Sungkyunkwan University in 2020. He has served as a principal researcher of Korea Institute of Science and Technology Information (KISTI). At present, he participates in the EDISON (ED-ucation-research Integration through Simulation On the Net) project, which is a web-based simulation service for education and research. He is interested in policies for HPC and computational science and engineering. 